\title{
Intrauterine adhesiolysis is a risk factor for abnormal placentation in subsequent pregnancies
}

\author{
Tirso Pérez-Medina \\ Department of OB/Gyn, Puerta de Hierro University Hospital, Autónoma University of Madrid, Madrid, Spain \\ Correspondence to: Tirso Pérez-Medina. Department of OB/Gyn, Puerta de Hierro University Hospital, Autónoma University of Madrid, Madrid, \\ Spain. Email: tirso.perez@salud.madrid.org. \\ Provenance and Peer Review: This article was commissioned by the Editorial Office, Annals of Translational Medicine. The article did not undergo \\ external peer review. \\ Comment on: Feng Q, Gao B, Huang H, et al. Obstetrical outcome in the third trimester after hysteroscopic adhesiolysis. Ann Transl Med $2020 ; 8: 51$.
}

Submitted Jan 25, 2020. Accepted for publication Feb 10, 2020.

doi: $10.21037 / \mathrm{atm} .2020 .02 .75$

View this article at: http://dx.doi.org/10.21037/atm.2020.02.75

Intrauterine adhesion (IUA) is one of the most challenging conditions related to fertility, given the occurrence of recurrent pregnancy losses and infertility along with the difficulty to restore the size and shape of the uterine cavity, as well as the endometrial function and the fertility.

Eventually, once the pregnancy is ongoing, some problems arise derived from the initial condition. When IUA are firm or severe, injury to the endometrium can destroy his deepest layers, the endometrial stroma and reach the myometrium. Restoring the cavity implies resection or destruction of the fibrous tissue that forms the adhesion, so leaving myometrial and endometrial scary areas with a compromised ability to restore the normal endometrium given the altered vascularization of these areas. If myometrial adhesions are present, as usual, after adhesiolysis, the endometrial basalis layer may not facilitate the proliferation of the functionalis layer and allow the regrowth of normal endometrium. These areas are coated by normal endometrium from adjacent places, so they are apparently (hysteroscopically) healthy. However, when the placentation process occurs, the placental growing tissue may invade deeper this thinned area, giving rise to altered placentation problems (AIP) (1).

In this issue of $A T M$, Feng et al. (2) present a retrospective cohort study in a group of 146 pregnant patients in which IUA adhesiolysis had been performed. They were compared with a matched control group of 292 patients without IUA antecedents. They present their results concerning the obstetric outcomes of these patients.
They find an OR of 19.93 (33.6\% vs. 2.7\%) for AIP (accreta, increta and precreta), an OR of 3.78 (11.6\% vs. $3.1 \%)$ for placenta previa (PP) (complete, marginal, partial, and low-lying placenta) and an OR of $5(42.5 \%$ vs. $8.6 \%)$ for retained placenta (RP). One out of every three patients had an AIP, including severe cases as placenta increta and accreta. Surprisingly, there was no need for any postpartum hysterectomy. Apart from the peculiar fact that $45.2 \%$ (132 patients) in the control group underwent cesarean section, the increase in placental alterations (AIP, PP and $\mathrm{RP}$ ) in IUA pregnant women must be highlighted.

Roy et al., studying a cohort of 36 women with Asherman syndrome who become pregnant following hysteroscopic adhesiolysis, reports on 4 patients (12.5\%) with all types of AIP (3).

Yu et al., evaluating reproductive outcomes after hysteroscopic adhesiolysis, found that 5 out of 25 (25\%) pregnant patients, who delivered after hysteroscopic adhesiolysis, presented AIP, with 2 hysterectomies due to uncontrolled hemorrhage for placenta accreta (4).

Deans, in her series with 93 pregnancies in 79 women, had 7 AIP (8.2\%), 7 PP (8.2\%) and 4 hysterectomies (4.7\%) (5). Additionally, 13 patients (13.3\%) underwent manual removal of the placenta and 13 more (13.3\%) postpartum hemorrhage.

In a retrospective study of 357 women who underwent hysteroscopic adhesion resection and were followed for a mean of $27 \pm 9$ months, 11 patients $(7.9 \%)$ had postpartum hemorrhage, including 6 (4.3\%) due to adherent placenta 
and $3(2.1 \%)$ due to placenta accreta (6).

Surgical trauma to the uterine cavity damages the endometrial mucosa. When this trauma reaches the stromal layer of the endometrium, the physiological regeneration of the endometrium is a little more difficult. When the trauma reaches the myometrium (aggressive D\&C, adhesiolysis), the potential for regeneration is compromised. When a pregnancy occurs, the myometrial fibrous scar hinders the normal process of placentation, in which cytotrophoblastic cells proliferate and differentiate into an invasive phenotype that invade (interstitial trophoblast) the maternal decidual stroma and the spiral arteries (endovascular trophoblast) of the myometrium, giving rise to abnormal implantation and its associated problems (accretism, intrauterine fetal growth restriction, preterm delivery, etc.).

The suspicion of AIP must be ruled out prenatally by means of sonography or magnetic resonance imaging (MRI), although the accuracy of these methods is not perfect and the criteria for a reliable diagnosis pre- and post-operatively are not uniform.

In one systematic review and meta-analysis of 20 studies of prenatal sonographic identification of AIP, the sensitivity was approximately $87 \%$, and specificity was approximately 98\% (7) in patients not blinded to the operator. On the other side, in study in which ultrasonographers were blinded to the clinical story of the patients the accuracy was lower (sensitivity 53\%) (8), raising some doubts about the ultrasound performance in AIP situations. Even more, the sonographic findings are not standardized allowing some degree of subjectivity.

MRI is useful for the diagnosis of AIP spectrum. However, increased accuracy over sonography is not proven. In a recent systematic review and meta-analysis of 20 studies with 1,080 pregnant women with ultrasound suspicion or presence of clinical risk factors for AIP, MRI had a global sensitivity of $94 \%$ and a specificity of $97 \%$ (9).

To reach a good accuracy in AIP, it is fundamental that the findings of sonography and MRI are assessed jointly and interpreted by trained radiologists.

In summary, it is important to be aware of the risk of altered placental implantation in those pregnant patients with a history of IUAs. The women candidates for hysteroscopic adhesiolysis must be thoroughly counselled regarding subsequent pregnancy and their risks associated before the procedure. Once pregnancy achieved, they must be considered as high-risk pregnancy and should be surveilled and managed consequently. A thorough prenatal diagnosis regarding placentation is essential and an appropriate setting for the delivery with advanced resources (blood bank, radiological facilities, expert surgeons, and neonatal care) must be provided.

\section{Acknowledgments}

Funding: None.

\section{Footnote}

Conflicts of Interest: The author has no conflicts of interest to declare.

Ethical Statement: The author is accountable for all aspects of the work in ensuring that questions related to the accuracy or integrity of any part of the work are appropriately investigated and resolved.

Open Access Statement: This is an Open Access article distributed in accordance with the Creative Commons Attribution-NonCommercial-NoDerivs 4.0 International License (CC BY-NC-ND 4.0), which permits the noncommercial replication and distribution of the article with the strict proviso that no changes or edits are made and the original work is properly cited (including links to both the formal publication through the relevant DOI and the license). See: https://creativecommons.org/licenses/by-nc-nd/4.0/.

\section{References}

1. Orhue AA, Aziken ME, Igbefoh JO. A comparison of two adjunctive treatments for intrauterine adhesions following lysis. Int J Gynaecol Obstet 2003;82:49-56

2. Feng Q, Gao B, Huang H, et al. Obstetrical outcome in the third trimester after hysteroscopic adhesiolysis. Ann Transl Med 2020;8:51.

3. Roy KK, Baruah J, Sharma JB, et al. Reproductive outcome following hysteroscopic adhesiolysis in patients with infertility due to Asherman's syndrome. Arch Gynecol Obstet 2010;281:355-61.

4. Yu D, Li TC, Xia E, et al. Factors affecting reproductive outcome of hysteroscopic adhesiolysis for Asherman's syndrome. Fertil Steril 2008;89:715-22.

5. Deans R, Vancaillie T, Ledger $W$, et al. Live birth rate and obstetric complications following the hysteroscopic management of intrauterine adhesions including Asherman syndrome. Hum Reprod 2018;33:1847-53.

6. Chen L, Zhang H, Wang Q, et al. Reproductive Outcomes 
in Patients With Intrauterine Adhesions Following Hysteroscopic Adhesiolysis: Experience From the Largest Women's Hospital in China. J Minim Invasive Gynecol 2017;24:299-304.

7. Pagani G, Cali G, Acharya G, et al. Diagnostic accuracy of ultrasound in detecting the severity of abnormally invasive placentation: a systematic review and meta-analysis. Acta Obstet Gynecol Scand 2018;97:25-37.

Cite this article as: Pérez-Medina T. Intrauterine adhesiolysis is a risk factor for abnormal placentation in subsequent pregnancies. Ann Transl Med 2020;8(6):270. doi: 10.21037/ atm.2020.02.75
8. Bowman ZS, Eller AG, Kennedy AM, et al. Accuracy of ultrasound for the prediction of placenta accreta. Am J Obstet Gynecol 2014;211:177.e1-7.

9. Familiari A, Liberati M, Lim P, et al. Diagnostic accuracy of magnetic resonance imaging in detecting the severity of abnormal invasive placenta: a systematic review and metaanalysis. Acta Obstet Gynecol Scand 2018;97:507-20. 